\title{
Combined administration of selenium and meso-2, 3- dimercaptosuccinic acid on arsenic mobilization and tissue oxidative stress in chronic arsenic-exposed male rats
}

\author{
Manoj Modi, Megha Mittal, S.J.S. Flora
}

Division of Pharmacology and Toxicology, Defence Research and D evelopment Establishment, Jhansi

Road, Gwalior, India

Received: 6.12.2006

Revised: 11.2 .2007

Accepted: 17.4 .2007

Correspondence to:

S. J. S. Flora

E-mail: sjsflora@hotmail.com

\begin{abstract}
O bjective: The present study describes the effect of selenium either alone or in combination with meso-2, 3-dimercaptosuccinic acid (DMSA) against chronic arsenic poisoning in rats.

Materials and Methods: Male Wistar rats were exposed to $100 \mathrm{ppm}$ sodium arsenite in drinking water for eight months and treated thereafter with DMSA $(0.3 \mathrm{mmol} / \mathrm{kg}$ orally) either individually or in combination with selenium (Se, 6.3 or $12.6 \mu \mathrm{mol} / \mathrm{kg}$, intraperitoneally) once daily for five days. The effects of these treatments in influencing the arsenic (As)-induced changes in heme synthesis, hepatic, renal or brain oxidative stress were evaluated along with the As concentration in blood and soft tissues.

Results: Exposure to As significantly altered biochemical parameters related to the heme synthesis pathway, blood and organ (liver, kidney and brain) oxidative stress while increasing body As burden in animals. Treatment with DMSA alone significantly reduced the adverse effects related to most of these biochemical parameters as well as the As concentration in blood and tissues. On the other hand, co-administration of Se with DM SA had only limited additional beneficial effects (particularly tissue oxidative stress) over the individual effect of DMSA.

Conclusion: The above results suggest that Se administration during chelation affected by other agents had some beneficial effects on oxidative stress with no major additional beneficial effect on arsenic depletion.
\end{abstract}

KEY WO RDS: Arsenic toxicity, chelating agent, oxidative stress, rats, selenium, combination therapy.
Chronic arsenic (As) poisoning has been widely reported in the general population in many areas of the world. Arsenic exposure occurs by consumption of drinking water that naturally contains high amounts of inorganic forms of As. ${ }^{[1]} \mathrm{In}$ West Bengal, India, a large population is endemically exposed to inorganic As by drinking heavily contaminated groundwater through hand-pumped tubewells. ${ }^{[2]}$ Exposure to As may cause severe biochemical and pathological problems such as Blackfoot disease, ${ }^{[3]}$ hypertension, ${ }^{[4]}$ diabetes mellitus ${ }^{[5]}$ and cancers of the liver, kidney, lung and bladder in humans. ${ }^{[6]}$ Data is also available for the toxic effects of As on whole brain ${ }^{[7,8]}$ and in discrete regions ${ }^{[9,10]}$ of rats and mice.

Recent studies have suggested that As exerts its toxicity through the generation of reactive oxygen species (ROS), ${ }^{[11-13]}$ which include hydrogen peroxide and free radicals such as superoxide anions. Free radicals have previously been shown to be capable of damaging many cellular components such as DNA, ${ }^{[14]}$ proteins $^{[15]}$ and lipids. ${ }^{[16]}$ In addition, sodium arsenite has been shown to enhance heme oxygenase production, an indicator of oxidative stress. ${ }^{[17]}$ ROS participate in the induction of oxidative stress. Arsenicals can produce ROS in vitro ${ }^{[18-22]}$ and in vivo. ${ }^{\mid 23]}$ Most of these reports mentioned that ROS levels increased by arsenicals were suppressed by the addition of various scavengers for ROS or enzymatic antagonists of superoxide and hydrogen peroxide production, suggesting that hydroxyl radicals are produced through hydrogen peroxide resulting from superoxide.

The clinical choice for the treatment of arsenic poisoning is the administration of a sulfhydryl-containing chelator such as meso-2,3-dimercaptosuccinic acid (DMSA), 2,3-dimercaptopropane-1-sulfonate (DMPS) or British Anti Lewisite (BAL; 2,3-dimercaprol). These dimercapto chelators compete with 
sulfhydryl groups in tissues or enzymes for binding As (III), which results in the elimination of As. DMSA, a dithiol and an orally administered chelator belonging to the mercapto family has a vicinal thiol moiety which binds arsenic. Thus, it is a potentially useful drug for the treatment of arsenic poisoning ${ }^{[24,25]}$ and has the structural potential to serve as an antioxidant in vivo. ${ }^{\mid 26]} \mathrm{A}$ new trend in chelation therapy has emerged, which is to use combination therapy instead of monotherapy with individual

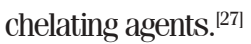

Co-administration of antioxidants such as vitamins $\mathrm{C}$ and $\mathrm{E}^{[28,29]}$ or N-acetyl cysteine ${ }^{[11]}$ and some essential metals such as zinc $^{[30]}$ during chelation therapy has been found to be beneficial in increasing arsenic mobilization and assisting the recovery of altered biochemical variables. Oxidative stress is one of the important mechanisms of arsenic-induced toxicity. Thus, it is expected that co-administration of an antioxidant like Se may be an important component of an effective chelation therapy. Selenium, an essential trace element for humans, is an essential component of glutathione peroxidase (GPx), an antioxidase enzyme, which plays a critical role in the body's antioxidant defense against oxidative damage by preventing the production of ROS. ${ }^{[31,32]}$ This enzyme together with superoxide dismutase (SOD), catalase and vitamin E neutralize ROS.

The interaction of Se with various metals produces protective effects in vitro and in vivo. ${ }^{228,33-35]}$ Arsenic and selenium are metalloids with similar chemical properties but with markedly different biological effects, Se being known to offer protection against arsenic toxicity. ${ }^{[36,37]}$ Protection against liver and kidney damage by Se was shown to be a result of enhanced antioxidant capacity of cells, as evidenced by increased SOD and glutathione reductase (GR) activities and elevated glutathione (GSH) content. ${ }^{|38|}$ Sodium selenite and selenomethionine were reported to protect against the genotoxic effects induced by As in human peripheral lymphocytes. ${ }^{[39]}$ Concurrent exposure to selenite interferes with the metabolism of arsenite and exacerbates the cytotoxic effects of arsenite and its trivalent methylated metabolites in cultured cells. Gregus et al. ${ }^{140]}$ noted that Se facilitates the excretion of inorganic As metabolites in rats. Selenium and arsenic each increase the biliary excretion of the other. ${ }^{[41]}$

We also recently reported that Se administration provided significant protection to the liver injury caused by As and provided more pronounced elimination of As in male rats. ${ }^{142]}$ Badiello et al. ${ }^{|43|}$ recently suggested that the administration of Se could provide a detoxifying action against metal ions, in addition to its antioxidant action. Thus, adequate or even extra Se in the diet may alleviate As toxicity. It is clear from the above mentioned studies that Se has got a significant role in protecting mice from the toxic effects of arsenite. However, selenium's beneficial role after arsenic exposure or during chelation treatment has not been explored. Thus, the present study was planned to evaluate the therapeutic potential of Se when given in combination with DMSA in depletion of As concentration in blood and other soft tissues postarsenic exposure and in providing recovery in the altered biochemical variables, indicative of oxidative stress organ injury.

\section{Materials and Methods}

\section{Chemicals and reagents}

Meso-2, 3-dimercaptosuccinic acid (DMSA), sodium arsenite and $\delta$-aminolevulinic acid (ALA) were procured from Sigma (St. Louis, MO, USA) while sodium selenite was obtained from Merck (Germany). All other analytical laboratory chemicals and reagents were purchased from Merck (Germany), Sigma or BDH Chemicals. Ultra pure water prepared using a Millipore apparatus (Millipore Company, New Delhi, India) was used throughout the experiment to avoid metal contamination and for the preparation of reagents / buffers used for various biochemical assays in our study. DMSA was stored in desiccator at $4^{\circ} \mathrm{C}$ to avoid oxidation and thermal decomposition and dissolved in $5 \%$ sodium bicarbonate solution. Sodium selenite was dissolved in distilled water. Solutions of DMSA and sodium selenite were prepared immediately before use. The dosing volume amounted to $4 \mathrm{ml} / \mathrm{kg}$ body weight.

\section{Animals and treatments}

All experiments were performed on male Wistar rats, each weighing approximately 100-120 g. Animals were obtained from the animal house facility of Defence Research and Development Establishment (DRDE), Gwalior. The Animal ethical committee of DRDE, Gwalior, India approved the protocols for the experiments. Prior to dosing, they were acclimated for seven days to light from 06:00 to 18:00 h alternating with $12 \mathrm{~h}$ darkness. The animals were housed in stainless steel cages (five rats/cage) in an air-conditioned room with temperature maintained at $25 \pm 2^{\circ} \mathrm{C}$. Rats were allowed standard rat chow diet (Amrut Feeds, Pranav Agro, New Delhi, India; Metal contents of diet in ppm, dry weight: $\mathrm{Cu}$ 10.0, Zn 45.0, Mn 55.0, Co 5.0, Fe 75.0) and water ad libitum throughout the experiment.

Thirty male Wistar rats were divided into two groups of five (control, group I) and twenty-five rats (group II) and were administered normal water (group I) and $100 \mathrm{ppm}$ sodium arsenite in drinking water (group II), respectively for eight months. After eight months, the 25 arsenic-exposed animals were divided into five groups of five rats / group and given the following treatment for 5 consecutive days:

Group IIA - Saline ( $4 \mathrm{ml} / \mathrm{kg}$ orally, once daily)

Group IIB - DMSA ( $0.3 \mathrm{mmol} / \mathrm{kg}$ orally, once daily)

Group IIC - Selenium as sodium selenite $(12.6 \mu \mathrm{mol} / \mathrm{kg}$, i.p, once daily)

Group IID - DMSA (as in group IIB) + Selenium $(6.3 \mu \mathrm{mol} / \mathrm{kg}$, i.p, once daily)

Group IIE - DMSA (as in group IIB) + Selenium (12.6 $\mu \mathrm{mol} / \mathrm{kg}$, i.p, once daily)

Arsenic exposure was stopped during the course of chelation treatment. A single dose of $0.3 \mathrm{mmol} / \mathrm{kg}$ of DMSA and 6.3 and $12.6 \mu \mathrm{mol} / \mathrm{kg}$ doses of Se were selected based on the results from previous experiments. ${ }^{[25,35]}$ Doses of DMSA and Se were given daily at six hour intervals. The food and water intake was recorded and rats were weighed every week. Forty-eight hours after the administration of the last dose, the animals were sacrificed under light ether anesthesia. Blood was collected by cardiac puncture in heparinized and nonheparinized vials (for serum). Liver, kidneys and brain were removed, rinsed in cold saline, blotted, weighed and used for various biochemical variables and metal analysis. Half portions of the liver and brain and one of the kidneys from all rats were processed immediately for biochemical estimation and the remaining portions were stored at $-20^{\circ} \mathrm{C}$ before wet acid digestion with $\mathrm{HNO}_{3}$ for estimation of As and Se concentrations. 


\section{Biochemical assay}

The activity of blood $\delta$-aminolevulinic acid dehydratase (ALAD) was assayed according to the procedure of Berlin and Schaller ${ }^{[44]}$ while white blood cells (WBC), red blood cells (RBC), hematocrit (Hct), hemoglobin (Hb), mean cell volume (MCV), mean cell hemoglobin (MCH) and mean cell hemoglobin concentration (MCHC) were measured by a Sysmex Hematology Analyzer (model K4500). Blood GSH concentration was determined by the procedure described by Ellman ${ }^{[45]}$ and modified by Jollow et al. ${ }^{[4]}$ Liver $\delta$-aminolevulinate synthase (ALAS) activity was measured by the method of Maines ${ }^{|47|}$ while brain, liver and kidney GSH and GSSG (oxidized GSH) levels were determined as described by Hissin and Hilf ${ }^{[48]}$ using a spectrofluorometer (Model RF 5000 Shimadzu, Japan). For the GSSG assay, the procedure described above for the GSH assay was followed except that $0.1 \mathrm{~mol} / \mathrm{L} \mathrm{NaOH}$ was used as the diluent instead of phosphate buffer.

Tissue SOD activity was assayed by the method of Nisshikimi et al. ${ }^{[49]}$ and modified by Kakkar et al. ${ }^{[50]}$ while catalase activity in tissues was assayed following Sinha's procedure. ${ }^{[51]}$ GPX activity was measured by the procedure of Flohe and Gunzler. ${ }^{52]}$ Tissue lipid peroxidation was measured by method of Ohkawa et al. ${ }^{[53]}$ Amount of ROS in the blood was measured using 2', 7'dichlorofluorescein diacetate (DCF-DA) that gets converted into highly fluorescent DCF by cellular peroxides (including hydrogen peroxide). Fluorescence was determined at an excitation wavelength of $488 \mathrm{~nm}$ and an emission wavelength of $525 \mathrm{~nm}$ using a fluorescence plate reader (Tecan Spectra Fluor Plus). The activities of alkaline Phosphatase (ALP) and acid phosphatase (ACP) were determined as described by Fiske and Subbarow. ${ }^{[54]}$ Alanine aminotransferase (ALT) and aspartate aminotransferase (AST) activities were measured in serum and liver. ${ }^{[55]}$

\section{Metal estimation}

Arsenic concentration in blood, liver, kidneys and brain were measured after wet acid digestion using a Microwave Digestion System (CEM, USA, model MDS-2100). Arsenic was estimated using a Hydride Vapour Generation System (Perkin Elmer model MHS-10) fitted with an atomic absorption spectrophotometer (AAS, Perkin Elmer model AAnalyst 100). Selenium concentration was also measured in the digested tissue samples using AAS..$^{[56]}$

\section{Statistical analysis}

Data is expressed as mean \pm SE (standard error). Data comparisons were carried out using one way analysis of variance followed by Bonferroni test to compare means between the different treatment groups. Differences between unexposed (with or without chelation) with a $P$ value $<0.05$ were considered statistically significant.

\section{Results}

Effects of Se, DMSA or their combination on as-induced changes in some hematological variables

Exposure to As significantly inhibited blood ALAD activity while marginally (not significantly) decreasing GSH levels. Although Reactive oxygen species (ROS) levels showed a significant increase on As exposure, there was no marked effect on hemoglobin and hematocrit in As-exposed rats. Treatment with DMSA alone reduced ROS levels and resulted in an increase in blood ALAD activity. Administration of Se (12.6 $\mu \mathrm{mol})$ significantly decreased ROS levels while it had no effect on any other biochemical variables. Combined administration of Se and DMSA on the other hand, had no additional beneficial effects over the individual effects of DMSA [Table 1].

The effects of As and chelation treatment on a few additional hematological variables in As-exposed rats were also determined. Chronic As exposure caused significant decrease in WBC counts however, no statistically significant changes were observed in RBC, MCV, MCH, MCHC and platelet levels (Data not shown). Except for increased WBC counts following combined administration of Se (at lower dose) and DMSA, no effect of chelating agent, selenium or their concomitant administration was noted on any of these hematological variables.

Effects of Se, DMSA or their combination on biochemical variables indicative of hepatic oxidative stress

Arsenic exposure led to a significant depletion of hepatic GSH levels and an increase in thiobarbituric acid-reacting substances (TBARS) levels. Liver ALAD activity also showed a significant decrease accompanied by a marked elevation in ALAS activity suggesting disturbed porphyrin metabolism. No effect on SOD activity was noted while catalase and GPX activities showed significant decrease. Postarsenic exposure treatment with DMSA provided significant recovery in hepatic TBARS levels and ALAD activity. Administration of Se alone had no effect on the above biochemical variables although concomitant administration of Se (at the dose of $6.3 \mu \mathrm{mol}$ ) with DMSA was marginally better than monotherapy with the chelating agent [Table 2].

\section{Table 1}

Effects of selenium, DMSA and their combination on arsenic-induced changes in hematological parameters in arsenic-exposed rats

\begin{tabular}{|c|c|c|c|c|c|c|}
\hline & Normal & Saline & DMSA & Se, 12.6 & $D M S A+S e, 6.3$ & $D M S A+S e, 12.6$ \\
\hline ALAD & $10.45 \pm 1.23^{*}$ & $4.97 \pm 0.44^{\dagger}$ & $6.27 \pm 0.51^{\ddagger}$ & $4.26 \pm 0.78^{\dagger}$ & $6.34 \pm 0.99 \ddagger$ & $6.48 \pm 1.08^{\ddagger}$ \\
\hline GSH & $3.42 \pm 0.06^{*}$ & $2.90 \pm 0.04^{*}$ & $3.20 \pm 0.04^{*}$ & $2.68 \pm 0.12^{*}$ & $3.29 \pm 0.07^{*}$ & $2.99 \pm 0.04^{*}$ \\
\hline ROS & $2.31 \pm 0.39^{*}$ & $3.97 \pm 0.46^{\dagger}$ & $2.82 \pm 0.28^{*}$ & $2.94 \pm 0.61^{*}$ & $1.94 \pm 0.12^{*}$ & $2.06 \pm 0.11^{*}$ \\
\hline $\mathrm{Hb}$ & $14.57 \pm 0.13^{*}$ & $13.86 \pm 0.03^{*}$ & $14.52 \pm 0.33^{*}$ & $13.80 \pm 0.25^{*}$ & $12.22 \pm 0.42^{*}$ & $13.06 \pm 0.32^{*}$ \\
\hline Hct & $42.53 \pm 0.48^{*}$ & $40.30 \pm 0.48^{*}$ & $41.62 \pm 0.91^{*}$ & $39.10 \pm 0.64^{*}$ & $38.40 \pm 0.80 *$ & $37.26 \pm 1.24^{*}$ \\
\hline
\end{tabular}

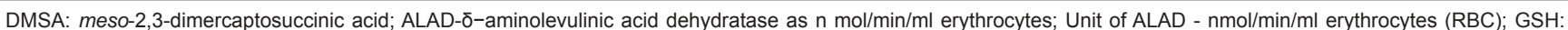

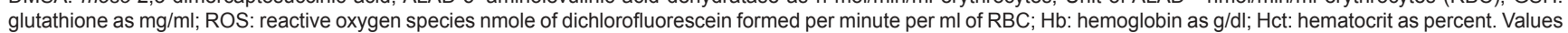
are mean $\pm \mathrm{SE} ; \mathrm{n}=5 .{ }^{*},{ }^{\dagger},{ }^{\ddagger}$ Differences between values with matching symbol notations within each row are not statistically significant at $5 \%$ level of probability 
Table 2

Effects of selenium, DMSA and their combination on biochemical parameteres indicative of hepatic oxidative stress in rats

\begin{tabular}{|c|c|c|c|c|c|c|}
\hline & Normal & Saline & DMSA & Se, 12.6 & $D M S A+S e, 6.3$ & $D M S A+S e, 12.6$ \\
\hline GSH & $5.74 \pm 0.45^{\star}$ & $4.44 \pm 0.22^{\dagger}$ & $4.26 \pm 0.37^{\dagger}$ & $3.40 \pm 0.35^{\dagger}$ & $5.29 \pm 0.34^{*}$ & $4.50 \pm 0.13^{\dagger}$ \\
\hline GSSG & $0.64 \pm 0.02^{*}$ & $0.70 \pm 0.01^{*}$ & $0.69 \pm 0.01^{*}$ & $0.63 \pm 0.02^{*}$ & $0.64 \pm 0.06^{*}$ & $0.71 \pm 0.05^{*}$ \\
\hline TBARS & $5.16 \pm 0.53^{*}$ & $7.98 \pm 0.37^{\dagger}$ & $5.96 \pm 0.16^{*}$ & $6.20 \pm 0.45^{*}$ & $5.62 \pm 0.27^{*}$ & $5.18 \pm 0.18^{*}$ \\
\hline Catalase & $14.12 \pm 0.19^{*}$ & $11.87 \pm 0.10^{\dagger}$ & $12.35 \pm 0.13^{\dagger}$ & $11.28 \pm 1.85^{\dagger}$ & $13.99 \pm 0.12^{*}$ & $10.51 \pm 0.29^{\dagger}$ \\
\hline SOD & $2.95 \pm 0.15^{\star}$ & $2.55 \pm 0.26^{*}$ & $2.46 \pm 0.30^{*}$ & $2.43 \pm 0.25^{\star}$ & $2.89 \pm 0.10^{*}$ & $2.56 \pm 0.17^{*}$ \\
\hline GPx & $7.57 \pm 0.59^{*}$ & $6.20 \pm 0.39^{\dagger}$ & $6.28 \pm 0.25^{\dagger}$ & $7.22 \pm 0.45^{\star}$ & $7.29 \pm 0.30^{*}$ & $7.16 \pm 0.36^{*}$ \\
\hline$A L A D$ & $52.03 \pm 5.92^{*}$ & $32.63 \pm 4.47^{\dagger}$ & $46.11 \pm 2.88^{*}$ & $33.17 \pm 5.81^{\dagger}$ & $46.64 \pm 3.14^{*}$ & $38.11 \pm 3.09^{\dagger}$ \\
\hline ALAS & $12.32 \pm 0.42^{*}$ & $16.34 \pm 0.75^{\dagger}$ & $16.20 \pm 0.68^{\dagger}$ & $15.84 \pm 0.89^{\dagger}$ & $16.10 \pm 0.70^{\dagger}$ & $15.70 \pm 0.36^{\dagger}$ \\
\hline
\end{tabular}

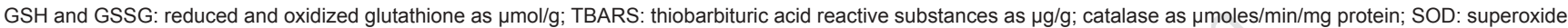

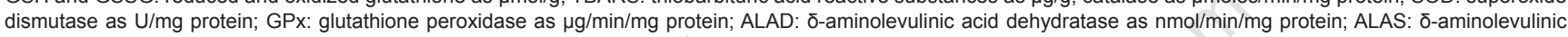

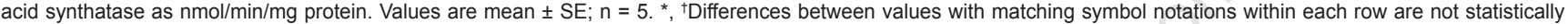
significant at $5 \%$ level of probability

Effects of Se, DMSA or their combination on biochemical variables indicative of hepatic damage

Table 3 shows biochemical variables indicative of liver damage. Arsenic exposure caused significant decrease in hepatic ALP and ACP activities while, serum AST and ALT activities showed increases. Treatment with DMSA and Se had no effect on any of these biochemical variables.

Effects of Se, DMSA or their combination on biochemical variables indicative on renal oxidative stress

Table 4 shows the changes in biochemical variables suggestive of renal oxidative stress in As-exposed rats treated with DMSA alone or in combination with Se. There was a significant increase in TBARS levels accompanied by a decreased catalase activity in kidneys of As-exposed animals. Renal GSH, GSSG levels and SOD activities remained unaltered on As exposure. Treatments with Se and DMSA alone were able to significantly reduce the increases in TBARS levels while no beneficial effect on catalase activity was observed. Concomitant administration of Se also had no additional beneficial effects over the effect of monotherapy with DMSA.

Effects of Se, DMSA or their combination on biochemical variables indicative of brain oxidative stress

Brain GSH showed significant depletion while GSSG, GPx and SOD activities remained unchanged and brain TBARS level increased significantly on arsenic exposure. Treatment with DMSA significantly increased brain GSH content while both DMSA and Se individually provided significant recovery in TBARS levels while no effects on other brain biochemical variables were observed [Table 5].

\section{Effects of Se, DMSA or their combination on arsenic concentration}

The increased As concentration in blood, liver and kidneys was significantly reduced by DMSA except for brain As levels which did not show any significant depletion [Figure 1]. Administration of Se alone had no effect on As concentrations but when given in combination particularly with at a lower dose with DMSA led to more pronounced depletion of liver and kidney As concentrations. No effect of combination treatment on blood and brain As concentrations was noted.

Effects of Se, DMSA or their combination on Se concentration

Selenium concentration increased in blood, liver, kidney
Figure 1: Effect of selenium, DMSA and their combination on arsenic concentration in blood and tissues of arsenic-exposed rats.

Units: Blood arsenic concentration as $\mathrm{ng} / 100 \mathrm{ml}$; tissue arsenic concentration as $\mu \mathrm{g} / \mathrm{g}$. Values are mean $\pm \mathrm{SE} ; n=5$. *,+,,$\S$ Differences between values with matching symbol notations within each bar are not statistically significant at $5 \%$ level of probability.

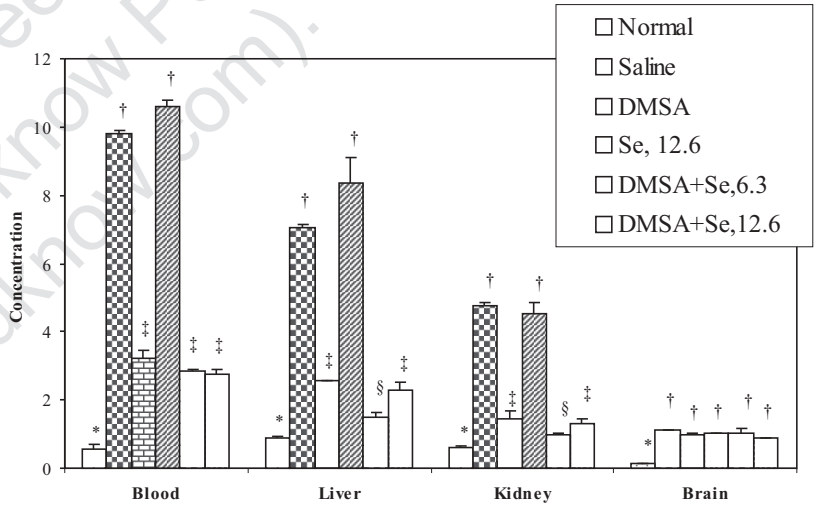

Figure 2: Effect of selenium, DMSA and their combination on selenium concentration in blood and tissues of arsenic-exposed rats.

Units: Blood Se concentration as $\mu \mathrm{g} / \mathrm{ml}$; tissue Se concentration as $\mu \mathrm{g} / \mathrm{g}$. Values are mean $\pm \mathrm{SE} ; n=5$. $*,+\neq$ Differences between values with matching symbol notations within each bar are not statistically significant at $5 \%$ level of probability.




Table 3

Effects of selenium, DMSA and their combination on some biochemical parameters indicative of hepatic injury in rats

\begin{tabular}{cccccc}
\hline & Normal & Saline & DMSA & Se, 12.6 & DMSA+Se, 6.3 \\
\hline Liver & & & & & \\
ACP & $0.69 \pm 0.09^{*}$ & $0.38 \pm 0.06^{\dagger}$ & $0.39 \pm 0.04^{\dagger}$ & $0.45 \pm 0.03^{\dagger}$ & $0.46 \pm 0.06^{\dagger}$ \\
ALP & $0.14 \pm 0.02^{*}$ & $0.06 \pm 0.02^{\dagger}$ & $0.09 \pm 0.01^{\dagger}$ & $0.10 \pm 0.01^{\dagger}$ & $0.10 \pm 0.03^{\dagger}$ \\
Serum & & & & \\
AST & $1.33 \pm 0.23^{*}$ & $1.80 \pm 0.06^{\dagger}$ & $1.65 \pm 0.09^{\dagger}$ & $2.11 \pm 0.34^{\dagger}$ & $0.09 \pm 0.01^{\dagger}$ \\
ALT & $0.44 \pm 0.05^{*}$ & $0.62 \pm 0.02^{\dagger}$ & $0.66 \pm 0.06^{\dagger}$ & $0.59 \pm 0.03^{\dagger}$ & $1.77 \pm 0.13^{\dagger}$ \\
ALP & $0.09 \pm 0.002^{*}$ & $0.12 \pm 0.008^{*}$ & $0.12 \pm 0.004^{*}$ & $0.14 \pm 0.03^{*}$ & $0.58 \pm 0.05^{\dagger}$ \\
\end{tabular}

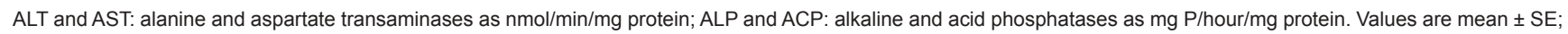
$n=5 .{ }^{*},{ }^{\dagger}$ Differences between values with matching symbol notations within each row are not statistically significant at $5 \%$ level of probability

\section{Table 4}

Effects of selenium, DMSA and their combination on biochemical parameters indicative of renal oxidative stress in rats

\begin{tabular}{|c|c|c|c|c|c|c|}
\hline & Normal & Saline & DMSA & Se, 12.6 & $D M S A+S e, 6.3$ & $D M S A+S e, 12.6$ \\
\hline GSH & $2.78 \pm 0.22^{\star}$ & $2.51 \pm 0.18^{*}$ & $2.65 \pm 0.13^{*}$ & $2.56 \pm 0.18^{*}$ & $2.63 \pm 0.30^{*}$ & $2.80 \pm 0.37^{*}$ \\
\hline GSSG & $0.36 \pm 0.02^{*}$ & $0.39 \pm 0.02^{*}$ & $0.40 \pm 0.01^{*}$ & $0.38 \pm 0.01^{*}$ & $0.39 \pm 0.02^{*}$ & $0.42 \pm 0.03^{*}$ \\
\hline TBARS & $9.0 \pm 0.75^{*}$ & $12.0 \pm 0.61^{\dagger}$ & $10.54 \pm 0.39 \ddagger$ & $8.30 \pm 0.96^{*}$ & $9.78 \pm 0.58^{\ddagger}$ & $9.50 \pm 1.76^{\ddagger}$ \\
\hline Catalase & $17.42 \pm 1.14^{*}$ & $13.07 \pm 0.49^{\dagger}$ & $14.35 \pm 1.78^{\dagger}$ & $15.66 \pm 0.91^{\dagger}$ & $14.86 \pm 1.32^{\dagger}$ & $14.71 \pm 1.31^{\dagger}$ \\
\hline SOD & $3.12 \pm 0.15^{\star}$ & $2.56 \pm 0.24^{*}$ & $3.03 \pm 0.35^{\star}$ & $3.02 \pm 0.30^{*}$ & $3.21 \pm 0.31^{*}$ & $2.86 \pm 0.59^{*}$ \\
\hline
\end{tabular}

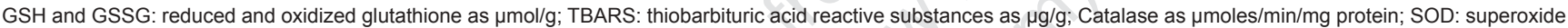

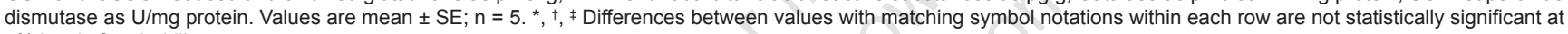
$5 \%$ level of probability

Table 5

Effects of selenium, DMSA and their combination on biochemical parameters indicative of brain oxidative stress in rats

\begin{tabular}{|c|c|c|c|c|c|c|}
\hline & Normal & Saline & DMSA & Se, 12.6 & $D M S A+S e, 6.3$ & $D M S A+S e, 12.6$ \\
\hline GSH & $3.15 \pm 0.36^{*}$ & $2.01 \pm 0.24^{\dagger}$ & $2.64 \pm 0.19^{*}$ & $2.18 \pm 0.22^{\dagger}$ & $2.83 \pm 0.16^{*}$ & $2.77 \pm 0.14^{*}$ \\
\hline GSSG & $0.30 \pm 0.01^{*}$ & $0.34 \pm 0.03^{*}$ & $0.32 \pm 0.02^{*}$ & $0.31 \pm 0.01^{*}$ & $0.31 \pm 0.02^{*}$ & $0.31 \pm 0.02^{*}$ \\
\hline GPx & $3.82 \pm 0.46^{*}$ & $2.97 \pm 0.31^{*}$ & $3.43 \pm 0.23^{*}$ & $2.81 \pm 0.14^{*}$ & $2.99 \pm 0.23^{*}$ & $3.02 \pm 0.23^{*}$ \\
\hline TBARS & $4.20 \pm 0.29^{*}$ & $6.50 \pm 0.14^{\dagger}$ & $4.37 \pm 0.20^{*}$ & $4.42 \pm 0.23^{*}$ & $4.35 \pm 0.14^{*}$ & $4.78 \pm 0.30^{*}$ \\
\hline SOD & $7.81 \pm 1.13^{*}$ & $5.57 \pm 0.57^{*}$ & $7.55 \pm 0.51^{*}$ & $5.42 \pm 0.44^{*}$ & $6.39 \pm 0.76^{*}$ & $5.46 \pm 0.56^{*}$ \\
\hline
\end{tabular}

GSH and GSSG: reduced and oxidized glutathione as $\mu \mathrm{mol} / \mathrm{g}$; GPx: glutathione peroxidase as $\mu \mathrm{g} / \mathrm{min} / \mathrm{mg}$ protein; TBARS: thiobarbituric acid reactive substances as $\mu \mathrm{g} / \mathrm{g}$; SOD: superoxide dismutase as $\mathrm{U} / \mathrm{mg}$ protein. Values are mean $\pm \mathrm{SE} ; \mathrm{n}=5 .{ }^{*},{ }^{\dagger}$ Differences between values with matching symbol notations within each row are not statistically significant at $5 \%$ level of probability

and brain of rats treated with Se. No effect of DMSA was noted on selenium concentrations in blood and tissues [Figure 2]. Administration of Se either alone or in combination with DMSA led to a significant increase in Se concentrations in these organs.

\section{Discussion}

The data from the present study provides a few interesting observations concerning the effects of Se during chelation treatment with DMSA in providing better recovery in Assensitive, altered biochemical and clinical variables compared to the individual effects of Se and DMSA. Such variables are indicative of oxidative stress, organ damage and altered heme synthesis pathway and mobilization of As from blood and other soft tissues of arsenic-exposed rats. It is evident from the results of the present investigation that administration of Se particularly at a dose of $6.3 \mu \mathrm{mol} / \mathrm{kg}$ of body weight with DMSA can lead to a more pronounced decrease in the liver and kidney levels of As and provided significant restoration of As-induced oxidative stress than monotherapy with DMSA.

Recent studies have suggested that As toxicity is associated with the induction of oxidative stress through the excessive generation of ROS and the inhibition of antioxidant enzymes. ROS include hydrogen peroxide and free radicals such as hydroxyl radical, superoxide anion, dimethyl arsenic peroxy and dimethylarsinic radicals in living systems. ${ }^{[1-13,20,57]}$ The result of the present work shows increased ROS generation in blood which also supports this hypothesis. In addition, sodium arsenite has been shown to enhance heme oxygenase production, an indicator of oxidative stress. ${ }^{[17]}$

In the present study, exposure to As led to a significant 
depletion of GSH in the blood and liver. GSH is a critical component of the oxidant defense system which helps in scavenging free radicals generated during As poisoning. ${ }^{[58]}$ GSH depletion may be responsible for the accumulation of free radicals that initiate lipid peroxidation (LPO) resulting in biochemical damage after covalent binding to biomacromolecules. GSH also protects the membrane polyunsaturated fatty acids from peroxidation and has an antioxidant function. ${ }^{[59]}$ GSH depletion also impairs hepatobiliary transport of arsenite ${ }^{[60]}$ as the lack of GSH prevents conversion of the trivalent arsenicals into labile GSH conjugates namely arsenotriglutathione $\left[\mathrm{As}(\mathrm{GSH})_{3}\right]$. This conjugate is a complex in which arsenic is bound to the thiol moieties of the cysteinyl residues of three GSH molecules. As(GSH) ${ }_{3}$ acts as a substrate for mrp-2, a primary active transporter in the bile canalicular membrane. ${ }^{[61]}$

In addition, the oxidized form of hepatic GSH (GSSG) showed a marginal increase (nonsignificant) in rats exposed to As. Increased formation of GSSG would be expected to increase production of hydrogen peroxide via GPx activity.

A significant inhibition of blood and liver ALAD activity was noted while ALAS activity increased in the liver of As-exposed rats. ALAD is the key enzyme that catalyzes the second step in heme biosynthesis in which two molecules of ALA are transformed into prophobilinogen, a heme precursor. ${ }^{[62]}$ The activity of ALAD is highly sensitive to the toxic effects of As. ${ }^{[63]}$ ALAD possesses thiol groups, which are essential for its activity. The diminished activity of ALAD as a result of As exposure could be caused by interference of As with the thiol groups resulting in the accumulation of ALA. ${ }^{[64]}$ Stimulation of ALAS activity also leads to increased ALA production and urinary excretion.

Earlier studies suggest that ROS produced due to ALA accumulation leads to the generation of oxidative stress and DNA damage. ${ }^{[6]}$ Inhibition of ALAD activity by As led to decreased heme synthesis and ultimately anemia. In the present study, As exposure produced a nonsignificant reduction of hemoglobin and a significant decrease in WBC counts which are in agreement with previous reports. ${ }^{[6]}$ This might be due to bone marrow depression following chronic exposure to As. The results also demonstrate that As induced a significant increase in lipid peroxidation (increased TBARS levels), a basic cellular process of deterioration of polyunsaturated fatty acids and occurs readily in the tissues rich in highly oxidizable polyunsaturated fatty acids. ${ }^{[67]}$

It is speculated that the increased lipid peroxidation is a result of the impairment of the endogenous antioxidant system by As and could be directly related to GSH depletion. The increase in lipid peroxidation was accompanied by a concomitant decrease in the antioxidant enzymes such as catalase, SOD and GPX. SOD and catalase are considered primary enzymes since they are involved in the direct elimination of ROS. ${ }^{[67]}$ SOD is an important defence enzyme, which catalyzes the dismutation of superoxide radicals $\left(\mathrm{O}_{2} \cdot-\right.$ to $\left.\mathrm{H}_{2} \mathrm{O}_{2}\right)$. Catalase is a heme protein, which catalyzes the reduction of hydrogen peroxides (converts $\mathrm{H}_{2} \mathrm{O}_{2}$ to oxygen and water) and protects tissues from highly reactive hydroxyl radicals. In the present study, catalase activity was reduced significantly in the liver and kidneys of As-exposed rats which could be due to the accumulation of superoxide anion radicals and hydrogen peroxide.

GPx, a Se-containing enzyme detoxifies $\mathrm{H}_{2} \mathrm{O}_{2}$ to $\mathrm{H}_{2} \mathrm{O}$ through the oxidation of GSH. Depression of GPx activity was observed in the liver of As-exposed animals. Decrease in the activity of GPX during As treatment indicates the reduction in the levels of GSH and increase in the levels of peroxides. The decreased acivity of GPx after As intoxication may arise because Se is a cofactor for GPx and As interacts with the essential selenocysteine moiety of the enzyme. ${ }^{[68]}$ Inhibition of antioxidant enzymes, viz., catalase and GPx in As-exposed animals also point to a disturbed antioxidant defence system of cells which might lead to generation of oxidative stress. Inorganic As compounds are known to be hepatotoxic. The determination of the activities of pathological enzymes like transaminases (AST and ALT) and phosphatases (ALP and ACP) is a common means of detecting liver damage. A significant decrease in hepatic ACP and ALP activities and a significant elevation of AST and ALT activities in serum without any significant change in serum ALP activity was noted following As exposure.

The current therapeutic approach to As poisoning is to increase the excretion of As by chelation. DMSA, a vicinal dithiol chelator has been reported to be effective in reducing lethality and chronic As toxicity in laboratory animals. ${ }^{[69]}$ It interacts with As in the cell forming a saturated five membered heterocyclic ring namely 1, 3-dithiol-2-arsolan. DMSA decreases the As burden in the cells by inhibiting the continuous production of ROS. ${ }^{[26]}$ In our study, we observed that DMSA alone marginally effected the inhibition of ALAD activity, significantly increased blood GSH levels, depleted TBARS in the liver and kidney and reduced ROS levels in blood. There was also a significant depletion of blood and soft tissue (liver and kidneys) As concentrations on DMSA administration. This could thus be attributed to the possibility that DMSA alone might be providing some recovery in biochemical variables indicative of oxidative stress by removing the As from the target organ and / or directly scavenging ROS via its sulfhydryl groups. ${ }^{[68]}$

It is plausible that impaired oxidant / antioxidant balance can be responsible for the toxic effect of As, hence, a therapeutic strategy to increase the antioxidant capacity of the cell is required to enhance the long-term effective treatment of As poisoning. It is well known that chelation therapy with many synthetic chelating agents is compromised with a number of side effects. ${ }^{[0]}$ A number of strategies have been suggested to minimize the numerous problems associated with chelation therapy. One of the important approaches has been the use of combination therapy. ${ }^{[69]}$ This prompted us to explore whether the co-administration of an antioxidant nutrient like Se during the removal of As by a a chelating agent could provide any additional advantage, i.e., abatement of the toxic effects of As. In the body, there are a number of Se-dependent activities involved in counteracting the toxicity of elements like As as well as the carcinogenicity of known as well as unknown chemical substances. The protective value of Se against oxidative injury is well known. ${ }^{[34,38]}$ Dimitrov et al. ${ }^{[11]}$ reported that Se is important in sulphur-containing amino acid metabolism.

Sulphur-containing amino acids protect animals against several diseases associated with low intake of Se and vitamin E. In this way, the sulphur-containing amino acids-methionine and cysteine can spare Se for antioxidant role. Selenium also maintains the levels of antioxidants, membrane-bound enzymes and the activities of antioxidant enzymes near normal levels 
thus, emphasizing their effects as antioxidants. Most studies so far have investigated the As-Se interaction to study its fate and biological activity ${ }^{[40,72]}$ while its effects when given in combination with a chelating agent postarsenic exposure have not been studied so far. The result of the present work showed that Se administration during chelation of As with DMSA affected the efficiency of the chelating agent in providing better reversal in a few altered biochemical variables. This was seen particularly in the reduction of As-induced oxidative stress and an effective removal of As from the liver and kidneys of Asexposed animals as compared to the individual effects of DMSA. It was suggested that Se did not affect the metabolism of the toxicant but appeared to enhance GSH-dependent mechanism of detoxification.

Similarities in the biotransformation of Se and inorganic As may account, at least in part for these interactions. In the course of their metabolism, As and Se may interfere with each other's fate directly and indirectly. ${ }^{172 \mid}$ The selenide metabolites of Se are reactive with As and can form a complex which probably decomposes due to its instability. Nevertheless, formation of the As-Se complex may have two corollaries (i) It may directly alter the distribution, biotransformation and excretion of the complexed metalloid (in the present study, As) and, (ii) The complexation decreases the concentration and consequently the effects of free As. Selenium is also known to decrease methionine adenosyl transferase. Selenium administration acutely decreases the hepatic concentration of S-adenosylmethionine (SAM) in mice and rats. ${ }^{|73|}$ Formation of the As-Se complex should lower the tissue concentration of free Se, thereby minimizing its SAM-depleting effects. The As-Se complex formed in the liver may be rapidly transported into bile with subsequent dissociation and release of As.

In our study, Se administration during chelation therapy provided no major additional benefits over the individual effects of DMSA, as far as depletion of As concentration is concerned. However, there were other prominent beneficial effects on altered biochemical variables. The study thus leads us to conclude that co-administration of Se with a chelating agent postarsenic exposure has limited beneficial effects particularly recovery in oxidative stress with no major additional beneficial effect on As concentration. Thus, it is recommended that a low dose of Se could be administered during chelation therapy in order to achieve better clinical benefits for an effective treatment of chronic As poisoning.

\section{Acknowledgments}

Authors thank Mr. K. Sekhar, Director of the establishment for his support and encouragement and ICMR, New Delhi for a Senior Research Fellowship.

\section{References}

1. Smith AH, Arroyo AP, Mazumder DN, Kosnett MJ, Hernandez AL, Beeris M, et al. Arsenic-induced skin lesions among Atacameno people in Northern Chile despite good nutrition and centuries of exposure. Environ Hlth Perspect 2000;108: $617-20$.

2. Chowdhury UK, Rahman MM, Mandal BK, Paul K, Lodh D, Biswas, et al. Groundwater arsenic contamination and human suffering in West Bengal, India and Bangladesh. Environ Sci 2000;8:393.

3. Tseng $\mathrm{CH}$, Chong CK, Chen CJ, Tai TY. Dose-response relationship between peripheral vascular disease and ingested inorganic arsenic among residents in Blackfoot disease endemic villages in Taiwan. Atherosclerosis 1996;120:12533.
4. Chen CJ, Hsueh YM, Lai MS, Shyu MP, Chen SY, Wu MM, et al. Increased prevalence of hypertension and long-term arsenic exposure. Hypertension 1995;25:53-60.

5. Lai MS, Hsueh YM, Chen CH, Shyu MP, Chen SY, Kuo TL, et al. Ingested inorganic arsenic and prevalence of diabetes mellitus. Am J Epidemiol 1994;139:484-92.

6. Hei TK, Filipic M. Role of oxidative damage in the genotoxicity of arsenic. Free Radic Biol Med 2004;37:574-81.

7. Tripathi N, Kannan GM, Pant BP, Jaiswal DK, Malhotra PR, Flora SJS. Arsenicinduced changes in certain neurotransmitter levels and their recoveries following chelation in rat whole brain. Toxicol Lett 1997;92:201-8.

8. Chaudhuri AN, Bast S, Chattopadhyay S, Gupta SD. Effect of high arsenic content in drinking water on rat brain. Indian J Biochem Biophys 1999;36:51-4.

9. Nagaraja TN, Desiraju T. Regional alterations in the levels of brain biogenic amines, glutamate, GABA and GAD activity due to chronic consumption of inorganic Arsenic in developing and adult rats. Bull Environ Contam Toxicol 1993;50:100-7.

10. Itoh $T$, Zhang YF, Murai $S$, Saito $H$, Nagahama $H$, Miyate $H$, et al. The effect of arsenic trioxide on brain monoamine metabolism and locomotor activity of mice. Toxicol Lett 1990;54:345-53.

11. Flora SJS. Arsenic induced oxidative stress and its reversibility following combined administration of $\mathrm{N}$-acetylcysteine and meso-2, 3 dimercaptosuccinic acid in rats. Clin Exp Pharmacol Physiol 1999;26:865-9.

12. Lee TC, Jan KY, Wang TC. Modulation of cellular antioxidant defense activities by sodium arsenite in human fibroblasts. Arch Toxicol 1995;69:498-504.

13. Ramos O, Carrizales L, Yanez L, Meija J, Batres L, Ortiz D, et al. Arsenic increased lipid peroxidation in rat tissues by a mechanism independent of glutathione levels. Environ Hlth Perspect 1995;103:85-8.

14. Liu J, Wang X, Shigenaga MK, Yeo HC, Mori A. Immobilization stress causes oxidative damage to lipid, protein and DNA in the brain of the rats. FASEB $\mathrm{J}$ 1996;10:1532-8.

15. Leeuwenburgh C, Hansen PA, Holloszy JO, Heinecke JW. Oxidized amino acids in the urine of aging rats: Potential markers for assessing oxidative stress in vivo. Am J Physiol 1999;276:R128-35.

16. Alper G, Girgin FK, Ozgonul M, Mentes G, Ersoz B. MAO inhibitors and oxidant stress in aging brain tissue. Eur Neuropsychopharmacol 1999;9:247-52.

17. Applegate LA, Luscher P, Tyrrell RM. Induction of heme oxygenase: A general response to oxidant stress in cultured mammalian cells. Cancer Res 1991;51: 974-8.

18. Gurr JR, Liu F, Lynn S, Jan KY. Calcium-dependent nitric oxide production is involved in arsenite-induced micronuclei. Mutat Res 1998;416:137-48.

19. Hei TK, Liu SX, Waldren C. Mutagenicity of arsenic in mammalian cells: Role of reactive oxygen species. Proc Nat Acad Sci USA 1998;95:8103-7.

20. Liu SX, Athar M, Lippai I, Waldren C, Hei TK. Induction of oxy radical by arsenic: Implication for mechanism of genotoxicity. Proc Natl Acad Sci USA 2001;98:1643-8.

21. Nordenson I, Beckman L. Is the genotoxic effect of arsenic mediated by oxygen free radicals? Hum Hered 1991;41:71-3.

22. Wang TS, Hsu TY, Chung CH, Wang AS, Bau DT, Jan KY. Arsenite induces oxidative DNA adducts and DNA-protein cross-links in mammalian cells. Free Radical Biol Med 2001;31:321-30.

23. Yamanaka K, Hasegawa A, Sawamura R, Okada S. Cellular response to oxidative damage in lung induced by the administration of dimethylarsinic acid, a major metabolite of inorganic arsenics, in mice. Toxicol Appl Pharmacol 1991;108:205-13.

24. Hantson P, Pharm HV, Buchet JP, Mahieu P. Acute arsenic poisoning treated by intravenous dimercaptosuccinic acid and combined extra renal depuration techniques. Clin Toxicol 2003:41:1-6.

25. Flora SJS, MehtaA, Rao PV, Kannan GM, Bhaskar AS, Dube SN, et al. Therapeutic potential of monoisoamyl and monomethyl esters of meso 2, 3- dimercaptosuccinic acid in gallium arsenide intoxicated rats. Toxicology 2004;195:127-46.

26. Ercal N, Treeratphan P, Hammond TC, Mattews RH, Grannemann N, Spitz D. In vivo indices of oxidative stress in lead exposed C57BL/6 mice are reduced by treatment with meso-2, 3-dimercaptosuccinic acid or $\mathrm{N}$-acetylcysteine. Free Radic Biol Med 1996;21:157-61.

27. Tandon SK, Dhawan M, Kumar A, Flora SJS. Influence of selenium supplementation during chelation of lead in rats. Indian J Physiol Pharmacol 1992;36:201-4.

28. Kannan GM, Flora SJS. Chronic arsenic poisoning in the rat: Treatment with combined administration of succimers and an antioxidant. Ecotoxicol Environ Saf 2004;58:37-43.

29. Ramanathan K, Balakumar BS, Panneer-Selvam C. Effects of ascorbic acid and $\alpha$-tocopherol on arsenic-induced oxidative stress. Hum Exp Toxicol 2002;21:67580 . 
30. Modi M, Pathak U, Kalia K, Flora SJS. Arsenic antagonism studies with monoisoamyl DMSA and zinc in male mice. Environ Toxicol Pharmacol 2005;19:131-8.

31. Ursini $F$, Bindoli $A$. The role of selenium peroxidases in the protection against oxidative damage. Chem Phys Lipids 1987;44:255-76.

32. Rayman MP. The importance of selenium to human health. Lancet 2000;356:233-41.

33. Flora SJS, Behari JR, Ashquin M, Tandon SK. Time-dependent protective effect of selenium against cadmium-induced nephrotoxicity and hepatotoxicity. Chem Biol Interact 1982:42:345-51.

34. Flora SJS, Kannan GM, Kumar P. Selenium effects on gallium arsenide induced biochemical and immunological changes in male rats. Chem Biol Interact 1999;122:1-13.

35. Naganuma A, Tanaka T, Maeda K, Matsuda R, Tabata-Hanyu J, Imura N. The interaction of selenium with various metals in vitro and In vivo. Toxicology 1983:29:77-86.

36. Andersen O, Nielsen JB. Effects of simultaneous low level dietary supplementation with inorganic and organic selenium on whole body, blood and organ levels of toxic metals in mice. Environ Hith Perspect 1994;102:321-4.

37. Schrauzer GN. Selenium: Mechanistic aspects of anticarcinogenic action. Biol Trace Elem Res 1992;33:51-62.

38. Othman Al, Missiry MA. Role of selenium against lead toxicity in male rats. $J$ Biochem Mol Toxicol 1998;12:345-9.

39. Hu G, Liu X, Liu J. Protective effects of sodium selenite and selenomethionine on genotoxicity to human peripheral lymphocytes induced by arsenic. Chin J Prev Med 1996;30:26-9.

40. Gregus A, Gyurasics A, Koszorus L. Interactions between selenium and group Va-metalloids (arsenic, antimony and bismuth) in the biliary excretion. Environ Toxicol Pharmacol 1998;5:89-99.

41. Levander OA, Baumann CA. Selenium metabolism. VI: Effect of arsenic on the excretion of selenium in the bile. Toxicol Appl Pharmacol 1966;9:106-15.

42. Modi M, Gupta R, Prasad GB, Flora SJS. Protective value of concomitant administration of trace elements against arsenic toxicity in rats. J Tissue Res 2004:4:257-62.

43. Badiello R, Feroci G, Fini A. Interaction between trace elements: Selenium and cadmium ions. J Trace Elem Med Biol 1996;10:156-62.

44. Berlin A, Schaller KH. European standardized method for the determination of delta aminolevulinic acid dehydratase activity in blood. Zeit Klin Chem Klin Biochem 1974; 12:389-90

45. Ellman GL. Tissue sulfhydryl groups. Arch Biochem 1959;82:70-7.

46. Jollow DJ, Mitchell JR, Zamppaglione Z, Gillette JR. Bromobenzene induced liver necrosis. Protective role of glutathione and evidence for 3,4-bromobenzene oxide as the hepatotoxic metabolites. Pharmacol 1974;11:151-5.

47. Maines MD. Regional distribution of the enzymes of haem synthesis and the inhibition of 5 -aminoleveulinate synthase by manganese in the rat brain. J Biochem 1980;190:315-21.

48. Hissin PJ, Hilf R. A fluorometric method for the determination of oxidized and reduced glutathione in tissues. Anal Biochem 1976;74:214-26.

49. Nishikimi M, Appaji N, YagiK. The occurrence of superoxide anion in the reaction of reduced phenazine methosulphate and molecular oxygen. Biochem Biophys Res Commun 1972;46:849-54.

50. Kakkar P, Das B, Viswanathan PN. A modified spectrophotometric assay of Superoxide dismutase. Indian J Biochem Biophys 1984;21:130-2.

51. Sinha AK. Colorimetric assay of catalase. Anal Biochem 1972;47:389-94.

52. Flohe L, Gunzler WA. Assays of glutathione peroxidase. Met Enzymol 1974;105:114-21.

53. Ohkawa H, Ohishi N, Yagi K. Assay for lipid peroxides in animal tissues by thiobarbituric acid reaction. Anal Biochem 1979;95:351-8.

54. Fiske $\mathrm{CH}$, Subbarow $\mathrm{Y}$. The colorimetric determination of phosphates. J Biol Chem 1925;66:375-9.

55. Reitman S, Frankel S. A calorimetric method for the determination of serum glutamic oxaloacetic and glutamic pyruvic transaminases. Am J Clin Pathol 1957;28:56-63

56. Marchante-Gayon JM, Sanchez-Uria JM, Sanz-Medel A. Serum and tissue selenium contents related to renal disease and colon cancer as determined by electrothermal atomic absorption spectrometry. J Trace Elem Med Biol 1966;10:229-36.

57. Flora SJS, Bhadauria S, Pant SC, Dhaked RK. Arsenic induced blood and brain oxidative stress and its response to some thiol chelators in rats. Life Sci 2005;77:2324-37.

58. Hwang $\mathrm{H}$, Huang $\mathrm{CF}$, Wu DR, Jinn CM, Jan KY. Glutathione as a cellular defense against arsenic toxicity in cultured Chinese hamster ovary cells. Toxicology 1993;79:195-204

59. Comporti M, Maellaro E, Del Bello B, Casini F. Glutathione depletion, its effects on other antioxidant systems and hepatocellular damage. Xenobiotica 1991;8:106776.

60. Gyurasics A, Varga F, Gregus Z. Glutathione-dependent biliary excretion of arsenic. Biochem Pharmacol 1991:42:465-8.

61. Kala SV, Neely MW, Kala G, Prater C, Atwood DW, Rice JR, et al. The MRP2/ cMOAT transporter and arsenic-glutathione complex formation are required for biliary excretion of arsenic. J Biol Chem 2000;275:33404-8.

62. Jaffe EK. Porphobilinogen synthase, the first source of heme's asymmetry. $J$ Bioenerg Biomembr 1995;27:169-79.

63. Bhadauria S, Flora SJS. Arsenic induced inhibited $\delta$-aminolevulinate dehydratase activity in rat blood and its response to meso- 2, 3-dimercaptosuccinic acid and monoisoamyl DMSA. Biomed Env Sci 2004;17:101-8.

64. Goyer RA, Clarkson TW. Toxic effects of metals. In: Klaassen CD, editor. Casarett and Doull's Toxicology. The Basic Science of Poisons. McGraw-Hill: USA; 2001. p. 830 .

65. Yusof M, Deniz Y, Ercal N. N-acetycysteine protects against $\delta$-aminolevulinic acid-induced 8-hydroxyguanosine formation. Toxicol Lett 1999;106:41-7.

66. Huges MF. Arsenic toxicity and potential mechanism of action. Toxicol Lett 2002;133:1-16.

67. Halliwell B, Gutteridge JM. Free radicals and toxicology. In: Free radicals in biology and medicine. Clarendon Press: Oxford; 1985. p. 1-27.

68. Schrauzer GN. Effects of selenium antagonists on cancer susceptibility: New aspects of chronic heavy metal toxicity. J UOEH 1987:9:208-15.

69. Flora SJS, Dube SN, Kannan GM, Arora U, Malhotra PR. Therapeutic potential of meso-2,3-dimercaptosuccinic acid and 2,3-dimercaptopropane 1-sulfonate against chronic arsenic poisoning in rats. Biometals 1995;8:111-7.

70. Flora SJS, Kumar P. Biochemical and Immunological evaluation of metal chelating drugs in rats. Drug Invest 1993:5:269-73.

71. Dimitrov NV, Ulrey DE, Primack S, Meyer C, Ku PK, Miller ER. Selenium as a metabolic modulator of phagocytosis. In: Selenium in biology and medicine, Part A. Van Nostrand Reinhold Co: New York; 1987. p. 254.

72. Csanaky I, Gregus Z. Effect of selenite on the disposition of arsenate and arsenite in rats. Toxicology 2003;186:33-50.

73. Gregus Z, Gyurasics A, Csanaky I, Pinter Z. Effects of methylmercury and organic acid mercurials on the disposition of exogenous selenium in rats. Toxicol Appl Pharmacol 2001;174:177-87.

74. Jorgensen FM. Succimer: The first approved oral lead chelator. Am Fam Physician 1993;48:1496-502. 